\title{
Commentary: Non-invasive Brain Stimulation, a Tool to Revert Maladaptive Plasticity in Neuropathic Pain
}

\author{
Marta Zantedeschi ${ }^{1}$ and Mariella Pazzaglia ${ }^{1,2 *}$ \\ ${ }^{1}$ Department of Psychology, University of Rome "La Sapienza," Rome, Italy, ${ }^{2}$ IRCCS Santa Lucia Foundation, Rome, Italy
}

Keywords: spinal cord injury, TMS, neuropathic pain, NIBS, plasticity, tDCS

\section{A commentary on}

Non-invasive Brain Stimulation, a Tool to Revert Maladaptive Plasticity in Neuropathic Pain by Naro, A., Milardi, D., Russo, M., Terranova, C., Rizzo, V., Cacciola, A., et al. (2016). Front. Hum. Neurosci. 10:376. doi: 10.3389/fnhum.2016.00376

Neuropathic pain (NP) is considered a definitive marker of maladaptive plasticity, which may be treated using non-invasive neuromodulatory techniques (Pascoal-Faria et al., 2015). In their stimulating and timely paper, Naro et al. (2016) review the significant progress made in studies of the use of non-invasive brain stimulation (NIBS) as an effective therapy to reduce chronic pain. The authors argued that NIBS interventions may induce neural changes that oppose the maladaptive plasticity at an early stage, thus representing a significant opportunity to prevent the development of NP.

As NP affects many individuals with spinal cord injury (SCI), this group may offer a model to test the above hypothesis. The reported prevalence of NP in SCI varies from $65-90 \%$ (Bonica,

OPEN ACCESS

Edited by:

Stephane Perrey,

University of Montpellier, France

Reviewed by:

Arko Ghosh,

University of Zurich, Switzerland

*Correspondence:

Mariella Pazzaglia

mariella.pazzaglia@uniroma1.it

Received: 10 August 2016 Accepted: 13 October 2016 Published: 27 October 2016

Citation:

Zantedeschi M and Pazzaglia M (2016) Commentary: Non-invasive Brain Stimulation, a Tool to Revert Maladaptive Plasticity in Neuropathic

Pain. Front. Hum. Neurosci. 10:544. doi: 10.3389/fnhum.2016.00544 1991; Siddall and Loeser, 2001; Siddall et al., 2003; Finnerup, 2013). The pain is severe and disabling in 18-63\% of cases (Hagen and Rekand, 2015), has a devastating impact on quality of life (Margot-Duclot et al., 2009), and is often refractory to medical treatment. Pain in SCI often begins immediately after onset of injury (Siddall et al., 2003), with reports of up to 75\% of cases presenting with early NP (Teixeira et al., 2013). Meanwhile, only 4-6\% report any improvement (Siddall and Loeser, 2001).

Commonly, NP in SCI has been attributed to maladaptive plasticity (Costigan et al., 2009). Several studies have demonstrated that deefferentation and deafferentation lead to profound and long-lasting functional and structural cortical reorganization (Wrigley et al., 2009; Freund et al., 2011; Henderson et al., 2011). In SCI, there appear to be numerous, complex changes in several brain areas involved in body motor, sensorial, and nociceptive processing, including primary and sensory cortices, and the anterior cingulate cortex (Lotze et al., 1999, 2006; Kokotilo et al., 2009). Dysfunctional and abnormal reorganization may occur secondary to altered spino-thalamic and spino-cerebellar input, and presumably reflects the adaptation of extensive neural networks to altered body signals (Bruehlmeier et al., 1998). This phenomenon leads to an imbalance in the excitatory and inhibitory inputs to somatosensory and motor cortices, which could lead to a maladaptive reorganization associated with the development and maintenance of pain (Wrigley et al., 2009; Soler et al., 2010b). Indeed, a significant relationship has been observed between the degree of cortical reorganization and the intensity and duration of ongoing pain, which has led to the assumption that NP is invariably associated with somatosensory cortex reorganization following complete SCI (Wrigley et al., 2009; Gustin et al., 2010). As such, those individuals 
displaying significant alterations in bodily neuronal activity that translate into long-term structural changes in the brain are more likely to develop NP (Gustin et al., 2010).

Despite these findings, recent evidence supports the possibility of a different view. The presence of below-level NP has been associated with preserved structure and function of the primary somatosensory and motor cortices (Mole et al., 2014). Furthermore, the ongoing nociception is hypothesized to prevent the development of a neural signature of maladaptive plasticity (Jutzeler et al., 2016), as is observed in amputees (Makin et al., 2013). These data showing that pain per se is not associated with cortical plasticity, suggest that NIBS treatments aimed at reversing cortical reorganization should consider other factors. Indeed, independent of whether pain induces, causes, or prevents ongoing maladaptive plasticity, a relationship seems to exist between the extent of the deafferented body and brain changes, as there exist structural and functional differences between people with and without pain. The critical factor required for the cortex to undergo functional reorganization is a disruption of bodily perception caused by the constant absence/alteration of sensorimotor input and output (Lucci and Pazzaglia, 2015).

Considering that approximately one-third of individuals with SCI develop NP in the paralyzed body parts below the level of injury (Yezierski, 2005), the cortical representation of the body within the sensory motor areas targeted by NIBS may be a critical factor for pain treatment. Evidence for a link between anatomical brain changes, body distortion, and pain emerge in SCI and other persistent pain conditions (Lotze and Moseley, 2007). Patients with pain describe an abnormal perception of the deafferented limb (heavy, floating, enlarged, and mislocated), while reductions in pain appear to be coincident with normalization of body representation, suggesting the link may be bidirectional (Pazzaglia and Zantedeschi, 2016). We have previously found that in complete SCI interventions, the affected body part can modulate the body representation and have powerful effects on pain (Lenggenhager et al., 2013; Pazzaglia and

\section{REFERENCES}

Bonica, J. J. (1991). History of pain concepts and pain therapy. Mt. Sinai J. Med. $58,191-202$.

Bruehlmeier, M., Dietz, V., Leenders, K. L., Roelcke, U., Missimer, J., and Curt, A. (1998). How does the human brain deal with a spinal cord injury? Eur. J. Neurosci. 10, 3918-3922. doi: 10.1046/j.1460-9568.1998.00454.x

Costigan, M., Scholz, J., and Woolf, C. J. (2009). Neuropathic pain: a maladaptive response of the nervous system to damage. Annu. Rev. Neurosci. 32, 1-32. doi: 10.1146/annurev.neuro.051508.135531

Finnerup, N. B. (2013). Pain in patients with spinal cord injury. Pain 154(Suppl. 1), S71-S76. doi: 10.1016/j.pain.2012.12.007

Freund, P., Weiskopf, N., Ward, N. S., Hutton, C., Gall, A., Ciccarelli, O., et al. (2011). Disability, atrophy and cortical reorganization following spinal cord injury. Brain 134, 1610-1622. doi: 10.1093/brain/awr093

Galli, G., Lenggenhager, B., Scivoletto, G., Molinari, M., and Pazzaglia, M. (2015). Don't look at my wheelchair! The plasticity of longlasting prejudice. Med. Educ. 49, 1239-1247. doi: 10.1111/medu.12834

Galli, G., and Pazzaglia, M. (2015). Commentary on: "The body social: an enactive approach to the self". A tool for merging bodily and social self in immobile individuals. Front. Psychol. 6:305. doi: 10.3389/fpsyg.2015.00305
Molinari, 2016; Pazzaglia et al., 2016). Such findings reveal the remarkable complexity and flexibility of body and pain plasticity in SCI, suggesting that a greater understanding of the cause of NP is necessary before any progress is made toward the application of the NIBS treatment.

Until now, isolated interventions applying both transcranial magnetic stimulation and transcranial direct current stimulation in SCI yielded conflicting results regarding the amelioration of pain. However, when NIBS and a visual illusion of the body were combined, the synergistic effects of the intervention produced better, and longer lasting analgesic benefits for reducing the overall severity of continuous NP compared with NIBS alone (Soler et al., 2010a).

Although the actual mechanisms underlying these effects remain to be elucidated, consideration of bodily perception opens the possibility of combined interventions with noninvasive procedures. These can be designed to preserve body representation and restore precise cortical topography, even when sensations are transferred to a different cortical territory. This may act as a means of preventing maladaptive plasticity and thereby prevent and manage refractory NP. The interplay between body awareness and pain as documented in visuallyinduced analgesia (Longo et al., 2012) bodily resizing (Mancini et al., 2011), allodynia (Pazzaglia et al., 2016), the use of virtual walking (Moseley, 2007; Soler et al., 2010a) and functional prostheses (Pazzaglia et al., 2013; Galli and Pazzaglia, 2015; Galli et al., 2015; Pazzaglia and Molinari, 2016) is imperative when considering current evidence supporting NIBS treatment, and will aid the rapid development of this potential rehabilitative therapy and the research supporting it. Clearly, more work is needed.

\section{AUTHOR CONTRIBUTIONS}

MP and MZ work conception and design, work revision, final approval, global agreement.
Gustin, S. M., Wrigley, P. J., Siddall, P. J., and Henderson, L. A. (2010). Brain anatomy changes associated with persistent neuropathic pain following spinal cord injury. Cereb. Cortex 20, 1409-1419. doi: 10.1093/cercor/bhp205

Hagen, E. M., and Rekand, T. (2015). Management of neuropathic pain associated with spinal cord injury. Pain Ther. 4, 51-65. doi: 10.1007/s40122-015-0033-y

Henderson, L. A., Gustin, S. M., Macey, P. M., Wrigley, P. J., and Siddall, P. J. (2011). Functional reorganization of the brain in humans following spinal cord injury: evidence for underlying changes in cortical anatomy. J. Neurosci. 31, 2630-2637. doi: 10.1523/JNEUROSCI.2717-10.2011

Jutzeler, C. R., Huber, E., Callaghan, M. F., Luechinger, R., Curt, A., Kramer, J. L., et al. (2016). Association of pain and CNS structural changes after spinal cord injury. Sci. Rep. 6:18534. doi: 10.1038/srep18534

Kokotilo, K. J., Eng, J. J., and Curt, A. (2009). Reorganization and preservation of motor control of the brain in spinal cord injury: a systematic review. J. Neurotrauma 26, 2113-2126. doi: 10.1089/neu.2008.0688

Lenggenhager, B., Scivoletto, G., Molinari, M., and Pazzaglia, M. (2013). Restoring tactile awareness through the rubber hand illusion in cervical spinal cord injury. Neurorehabil. Neural Repair 27, 704-708. doi: 10.1177/1545968313491009

Longo, M. R., Iannetti, G. D., Mancini, F., Driver, J., and Haggard, P. (2012). Linking pain and the body: neural correlates of visually induced analgesia. J. Neurosci. 32, 2601-2607. doi: 10.1523/JNEUROSCI.4031-11.2012 
Lotze, M., Laubis-Herrmann, U., and Topka, H. (2006). Combination of TMS and fMRI reveals a specific pattern of reorganization in M1 in patients after complete spinal cord injury. Restor. Neurol. Neurosci. 24, 97-107.

Lotze, M., Laubis-Herrmann, U., Topka, H., Erb, M., and Grodd, W. (1999). Reorganization in the primary motor cortex after spinal cord injury - A functional Magnetic Resonance (fMRI) study. Restor. Neurol. Neurosci. 14, $183-187$.

Lotze, M., and Moseley, G. L. (2007). Role of distorted body image in pain. Curr. Rheumatol. Rep. 9, 488-496. doi: 10.1007/s11926-007-0079-x

Lucci, G., and Pazzaglia, M. (2015). Towards multiple interactions of inner and outer sensations in corporeal awareness. Front. Hum. Neurosci. 9:163. doi: 10.3389/fnhum.2015.00163

Makin, T. R., Scholz, J., Filippini, N., Henderson Slater, D., Tracey, I., and Johansen-Berg, H. (2013). Phantom pain is associated with preserved structure and function in the former hand area. Nat. Commun. 4, 1570. doi: $10.1038 /$ ncomms 2571

Mancini, F., Longo, M. R., Kammers, M. P., and Haggard, P. (2011). Visual distortion of body size modulates pain perception. Psychol. Sci. 22, 325-330. doi: $10.1177 / 0956797611398496$

Margot-Duclot, A., Tournebise, H., Ventura, M., and Fattal, C. (2009). What are the risk factors of occurence and chronicity of neuropathic pain in spinal cord injury patients? Ann. Phys. Rehabil. Med. 52, 111-123. doi: 10.1016/j.rehab.2008.12.003

Mole, T. B., MacIver, K., Sluming, V., Ridgway, G. R., and Nurmikko, T. J. (2014). Specific brain morphometric changes in spinal cord injury with and without neuropathic pain. Neuroimage Clin. 5, 28-35. doi: 10.1016/j.nicl.2014.05.014

Moseley, G. L. (2007). Using visual illusion to reduce at-level neuropathic pain in paraplegia. Pain 130, 294-298. doi: 10.1016/j.pain.2007.01.007

Naro, A., Milardi, D., Russo, M., Terranova, C., Rizzo, V., Cacciola, A., et al. (2016). Non-invasive brain stimulation, a tool to revert maladaptive plasticity in neuropathic pain. Front. Hum. Neurosci. 10:376. doi: 10.3389/fnhum.2016.00376

Pascoal-Faria, P., Yalcin, N., and Fregni, F. (2015). Neural markers of neuropathic pain associated with maladaptive plasticity in spinal cord injury. Pain Pract. 15, 371-377. doi: 10.1111/papr.12237

Pazzaglia, M., Galli, G., Scivoletto, G., and Molinari, M. (2013). A functionally relevant tool for the body following spinal cord injury. PLOS ONE 8:e58312. doi: 10.1371/journal.pone.0058312

Pazzaglia, M., Haggard, P., Scivoletto, G., Molinari, M., and Lenggenhager, B. (2016). Pain and somatic sensation are transiently normalized by illusory body ownership in a patient with spinal cord injury. Restor. Neurol. Neurosci. 34:603-613. doi: 10.3233/RNN-150611

Pazzaglia, M., and Molinari, M. (2016). The embodiment of assistive devices-from wheelchair to exoskeleton. Phys. Life Rev. 16, 163-175. doi: 10.1016/j.plrev.2015.11.006

Pazzaglia, M., and Zantedeschi, M. (2016). Plasticity and awareness of bodily distortion. Neural Plast. 2016:9834340. doi: 10.1155/2016/9834340

Siddall, P. J., and Loeser, J. D. (2001). Pain following spinal cord injury. Spinal Cord 39, 63-73. doi: 10.1038/sj.sc.3101116

Siddall, P. J., McClelland, J. M., Rutkowski, S. B., and Cousins, M. J. (2003). A longitudinal study of the prevalence and characteristics of pain in the first 5 years following spinal cord injury. Pain 103, 249-257. doi: 10.1016/S03043959(02)00452-9

Soler, M. D., Kumru, H., Pelayo, R., Vidal, J., Tormos, J. M., Fregni, F., et al. (2010a). Effectiveness of transcranial direct current stimulation and visual illusion on neuropathic pain in spinal cord injury. Brain 133, 2565-2577. doi: 10.1093/brain/awq184

Soler, M. D., Kumru, H., Vidal, J., Pelayo, R., Tormos, J. M., Fregni, F., et al. (2010b). Referred sensations and neuropathic pain following spinal cord injury. Pain 150, 192-198. doi: 10.1016/j.pain.2010.04.027

Teixeira, M. J., Paiva, W. S., Assis, M. S., Fonoff, E. T., Bor-Seng-Shu, E., and Cecon, A. D. (2013). Neuropathic pain in patients with spinal cord injury: report of 213 patients. Arq. Neuropsiquiatr. 71, 600-603. doi: 10.1590/0004-282X20130103

Wrigley, P. J., Press, S. R., Gustin, S. M., Macefield, V. G., Gandevia, S. C., Cousins, M. J., et al. (2009). Neuropathic pain and primary somatosensory cortex reorganization following spinal cord injury. Pain 141, 52-59. doi: 10.1016/j.pain.2008.10.007

Yezierski, R. P. (2005). Spinal cord injury: a model of central neuropathic pain. Neurosignals. 14, 182-193. doi: 10.1159/000087657

Conflict of Interest Statement: The authors declare that the research was conducted in the absence of any commercial or financial relationships that could be construed as a potential conflict of interest.

Copyright (c) 2016 Zantedeschi and Pazzaglia. This is an open-access article distributed under the terms of the Creative Commons Attribution License (CC BY). The use, distribution or reproduction in other forums is permitted, provided the original author(s) or licensor are credited and that the original publication in this journal is cited, in accordance with accepted academic practice. No use, distribution or reproduction is permitted which does not comply with these terms. 